\title{
Powerful or pointless? Examining the effect of excel on business statistics success
}

\author{
Curtis Penrod, Northwestern State University of Louisiana, penrodc@nsula.edu \\ Mary Edith Stacy, Northwestern State University of Louisiana, maryedith@nsula.edu \\ Lily Pharris, Northwestern State University of Louisiana, pharrisl@nsula.edu \\ Mary Beth Tarver, Northwestern State University of Louisiana, tarverm@nsula.edu
}

\begin{abstract}
Successful completion of prerequisite coursework is paramount in preparing students to successfully complete of subsequent courses. However, as higher education stakeholders have placed an emphasis on roadblocks to student progression and success in college, programs of higher education may need to reassess whether prerequisites are necessary. The current study examines whether a prerequisite Spreadsheet Application course (CIS 2000) and MOS Certification exam taken by students attending a regional, public, four-year university is needed to adequately prepare students for successful completion of a Basic Business Statistics class (BUAD 2120). Utilizing three years of data, researchers conducted a correlational analysis between the students' MOS in Excel certification scores and the final grades in CIS 2000, the students' final grades in CIS 2000 and the final grades in BUAD 2120, and the students' MOS in Excel certification scores and the final grades in BUAD 2120. The results of the Pearson productmoment correlation showed significant relationships with varying degrees of strengths. As correlation is not causation, further study is needed to determine the true effect of the prerequisite knowledge on success in the BUAD 2120 class.
\end{abstract}

Keywords: Prerequisite course, Student success, Correlational analysis, Pearson product-moment correlation

\section{Introduction}

The School of Business at a regional, four-year public university in Louisiana offers AACSB accredited programs in Accounting, Business Administration, and Computer Information Systems. In recent years, encouraged by students, higher education administrators, and government officials seeking to address everincreasing tuition costs and fees across the university system, faculty in the School of Business have investigated ways to help students earn their degrees by eliminating roadblocks that may lengthen the timeto-graduation. One such roadblock investigated was unnecessary prerequisites.

To complete program requirements and earn their degrees, students majoring in business programs are required to pass BUAD 2120 - Basic Business Statistics, a basic statistical foundation course with emphasis placed upon practical business applications including hypothesis testing, ANOVA, contingency table analysis, and introductory regression analysis. Like many business schools around the world, the School of Business faculty have deemed the material covered in this basic statistics course to be necessary for preparing students for work in business and industry. Before taking BUAD 2120, all business majors must first pass two prerequisite courses: (1) a finite mathematics class or close equivalent, and (2) CIS 2000 - 


\section{Issues in Information Systems}

Volume 22, Issue 2, pp. 83-95, 2021

Spreadsheet Applications, a spreadsheet class that emphasizes mastery of Microsoft Excel concepts. The CIS 2000 class is open to all students across all fields of study. Students typically take the spreadsheet class as freshmen or sophomores and the business statistics course as sophomores or juniors.

In considering which prerequisite courses should be examined first, differing perspectives arose about the need for students to take the Microsoft Excel spreadsheet course prior to business statistics between the instructors of the two courses. While the instructor of CIS 2000 course held the position that taking Excel helps prepare students for Business Statistics, the instructor of BUAD 2120 expressed concerns that upon starting the business statistics course, in which students are required to utilize MS Excel in lieu of a calculator to complete all activities and assignments, students still did not know Excel well enough to perform basic statistical functions. The BUAD 2120 instructor also claimed that students had to relearn the knowledge they should have picked up in CIS 2000 prior to moving onto the current course material. Previous research can add additional insights into the discussion areas.

\section{Student Success: Predictors and Obstacles.}

According to Sparkman, Maulding, and Roberts (2012), much is to be gained when students succeed in the higher educational environment. Not only do students personally benefit from the gains in knowledge and skills, but the communities in which these students intermingle have been shown to profit from a wide range of value-added experiences as well. Still, students come from many backgrounds, and many encounter obstacles that can impede their ability to be successful in college (Duke \& Strawn, 2008). Determining the effect of these obstacles can help higher education faculty and staff assist students in overcoming them.

\section{GPA and Standardized Test Scores.}

To better understand and address the obstacles faced by students along their path to successful persistence in college, researchers have focused on various aspects surrounding why some students struggle while others are successful. Research indicates that a student's high school grade point average (GPA) and standardized test scores are consistently the best predictors of success in college (Sparkman et al., 2012), with the GPA considered the "single best predictor of ... degree completion" (Pascarella \& Terenzini, 2005, p. 396). Even so, researchers acknowledge that GPA is a limited measure of a student's success and learning, albeit an important benchmark that is widely used as students make progress towards graduation (Becker, 2014; Pascarella \& Terenzini, 2005). Thus, GPA is one possible measure of student success, but other predictors do exist.

\section{Other Factors}

Even so, while research has shown the reliability of high school GPA and standardized test scores as predictors of student success in college, other studies suggest that persistence may also rely on other variables, such as the student's emotional intelligence (Sparkman et al., 2012), behaviors and self-regulation (Yukselturk \& Bulut, 2007), or interactions with faculty and peers (Kuh, Kinzie, Buckley, Bridges, \& Hayek, 2006). Timmerman, Raymer, Gallgher, and Doom (2016) point out common barriers, such as student motivation, interest, opportunity, social skills, cognitive skills, and prior academic preparation may all present potential barriers that students may have to overcome on the road to achieving their dreams of earning a college degree. Doubly, first-generation college students often need to overcome added roadblocks related to their financial stability, college academic readiness, and support systems (Falcon, 2015). As these researchers have shown, other factors affecting student success include factors related to academic abilities, social abilities, financial support, and other support. 


\section{Issues in Information Systems}

Volume 22, Issue 2, pp. 83-95, 2021

\section{Curriculum and Coursework}

To address the various obstacles that students encounter on the path to earning a college degree, previous research has focused on the efforts of faculty and administrators to improve the curriculum and eliminate barriers to student success by reducing costs for students (Grace, \& D'aoust, 2006; Pharris, Tarver, \& Penrod, 2020), enhancing student learning (Hanna, Perdue, \& Waller, 2015) and preparing students for higher-level coursework (Plutsky \& Wilson, 2000; Ball, 1992). For example, a study by Gupta, Harris, Carrier, and Caron (2006) investigated the predictors of student success in entry-level undergraduate coursework, often the courses that provide the greatest impediment due to their low pass rates (Gupta, Harris, Carrier, \& Caron, 2006). After collecting and analyzing data on possible predictors of student grades related to student demographics, attitudes, educational experiences, and study time, Gupta et al. (2006) performed univariate and multivariate analysis on the data. The findings indicated that creating a supportive class setting and structure was important for improving student performance in an entry-level, barrier mathematics class. These findings were supported by Chickering and Kuh (2005) who examined the role of creating a learning environment conducive to promoting student success and Gainen (1995) who purported that faculty might successfully reduce student erosion in introductory courses by addressing various barriers to their success.

\section{Prerequisite Knowledge and Student Success}

An area that has garnered much attention in the body of literature is the role of prerequisite knowledge and coursework in relation to enhancing student success (Hudon, 2016; Ball, 1992). Results from a Soria and Mumpower (2012) study suggest prerequisites not only have a positive association with GPAs and retention rates, but they can also encourage students to build advising relationships with academic advisors. Undergraduate degree programs often expect students to complete prerequisite coursework to prepare them for subsequent major courses (Islam, Gygi, Gardner, \& Gooch, 2005). Similarly, Islam et al. (2005), explain that the goal of requiring students to successfully complete prerequisite classes prior to enrolling in major classes is to increase confidence, skills, and performance in the major classes, which, in turn, is expected to allay some of the anxiety students have often expressed about taking quantitative courses. As seen in a 1997 study by Zanakis and Valenzi, findings revealed that student anxiety and attitudes significantly affected student outcomes in a business statistics course, indicating the importance of investing in ways to help students address these issues if they hope to be successful in the degree program. Establishing prerequisites may come at a cost for business schools, though, as seen by Armstrong (1998) who noted that enforcing prerequisites corresponded with declining enrollment across most of the disciplines and within unique sections in the investigation. Abou-Sayf (2008) asserts that prerequisite courses are only justified if they increase students' chances for success or to ensure their safety, and it is important to remove prerequisites that act as barriers by blocking access or adding expense (Grace \& D'aoust, 2006). Given the need to increase student success and reduce expenses as the higher education level, justifying prerequisites is an important component of academic practice today.

\section{Business School Prerequisites}

In some schools, prerequisite courses are mandatory, while in others, they are recommended, but not enforced upon students. Wilkerson, Palmer, and Meyer (2019) argue that issues arise when business students enroll in target classes before taking the prerequisite. In one example of the importance of prerequisite knowledge for business programs, Sargent (2013) investigated how enforcing prerequisites impacted student outcomes in an intermediate accounting course, a program often offered by business schools. Students found to be proficient in the prerequisite skills earned higher project and cumulative final 


\section{Issues in Information Systems}

Volume 22, Issue 2, pp. 83-95, 2021

exam scores in areas not covered in the prerequisite course. In another study by Plutsky and Wilson (2000), researchers found that California State University Northridge undergraduate business administration students who completed their business computer literacy program performed considerably better in a business communications course than students that failed to complete the prerequisite program. A third study, by Hanna, Perdue, and Waller (2015) compared data from 336 students taking an investments class. Study results demonstrated that business students having successfully completed the recommended prerequisite performed significantly better than students not taking the recommended prerequisite or taking it at the same time as the target course.

\section{Business Statistics}

Business statistics is commonly considered the course upon which business schools rely to prepare students for subsequent coursework in business-related disciplines. In a study by Baard and Watts (2008), researchers compared the performance of students taking a Principles of Finance class from 2003 to 2006. Participants had either successfully completed Business Statistics, or they had not. The findings indicated that students who completed Business Statistics prior to taking Principles of Finance performed significantly better than those students that did not. This study closely aligns with research by Islam et al. (2005) which discusses why statistics is a fundamental skill for students attempting to earn an undergraduate business degree.

Unfortunately, even though statistical literacy is highly valued in college graduates and considered a fundamental skill for business, students regularly struggle to pass basic statistics classes (Sirias, 2002). Because students often struggle with learning difficult statistical concepts, researchers, Lai and Williams (2017), argue for various supports to be implemented to improve how students learn this essential skill and perform in business statistics classes. Some researchers advocate for the application of technology to enhance the learning process and performance of students in business statistics courses (Lai \& Williams, 2017; Sirias, 2002), while other studies found little evidence that the technologies used to teach statistics made much of a difference in student outcomes (Spinelli, 2001; Palocsay \& Stevens, 2008). Thus, a split in the literature exists between proponents of technology usage in statistics and those researchers who found little to support its usage.

\section{Prerequisite Knowledge for Business Statistics.}

Research promotes the use of prerequisite coursework to build the necessary skills for students to be successful in business statistics (Islam, Khan, Wilson, \& Gooch, 2008), particularly focusing on helping student build stronger math skills. In a 2007 study by Choudhury, Robinson, and Radhakrishnan, researchers examined differences in performance between two prerequisite courses and a targeted business statistics class. Students in the study that took Finite Mathematics course, which gave students a stronger mathematical foundation, performed significantly better than students taking Data and Chance as their prerequisite course. The Choudhury et al. (2007) findings support the need for students to enter business statistics with a stronger background in mathematics if they intend to be successful.

The need for students to possess a strong background in math prior to taking an introductory statistics class was more closely examined by Johnson and Kuennen (2006) who conducted a thorough review of the relationships between the math skills of students and student performance in a statistics course. The researchers analyzed several factors including whether students took calculus or business calculus, if they were required to take remedial math coursework, and how the student scored on a basic math concepts 


\section{Issues in Information Systems}

Volume 22, Issue 2, pp. 83-95, 2021

exam. The study also included an analysis of the student's ACT math placement score and the ACT science and reasoning placement score with their success in an introductory statistics class. Results revealed that ACT placement scores for math and science were each significantly associated with performance in the basic statistics course.

\section{Microsoft Excel as a Prerequisite to Business Statistics}

The current study adds to the body of literature by investigating student success in a prerequisite Microsoft Excel course on success in a basic business statistics course. While much of the literature cites the use of Microsoft Excel as a tool to enhance student learning in statistics (Anderson, Sweeney, Williams, Camm, \& Cochran, 2020; Jacobs, Robinson, \& DePaolo, 2019; Chaamwe \& Shumba, 2016), the review of literature revealed no studies that examined the relationship between Microsoft Excel as a prerequisite course and the success of students in business statistics course. The body of literature supports the need for students to possess specific prerequisite knowledge and skills if they hope to be successful in business programs. In fact, research by Kline and Strickland (2004), Hindi, Miller, and Wenger (2002), Duncan (1990) and Zhao (2002) confirms the relevance of personal computing and information technology skills to student success in business programs, but none of these studies discuss these skills as particularly important for business statistics. This study attempts to extend these studies further, by taking a closer look at the relationship between student success in Microsoft Excel and basic business statistics.

\section{Methodology}

The present study is designed to examine the relationship between two courses to determine whether the spreadsheet course helps prepare students to be successful in business statistics course and to review the necessity of prerequisite courses. The purpose of this research study is to determine to what extent can student success in a Basic Business Statistics course be attributed to success in the prerequisite Spreadsheet Applications course and the associated Microsoft Office Specialist (MOS) in Excel certification examination. Three research questions were investigated:

RQ1: Will success in CIS 2000 predict success on the MOS Excel certification?

RQ2: Will success in CIS 2000 predict success in BUAD 2120?

RQ3: Will success on the MOS in Excel exam predict success in BUAD 2120?

The research questions were investigated using historical data. The historical records obtained were the CIS 2000 final grade, the MOS Excel Examination score and the BUAD 2120 grade for students who had taken CIS 2000 beginning in the Fall 2016 semester thru the Summer 2019 semester. A total of eight semesters of data were available for this study. The CIS 2000 course was not taught during the Summer 2017 semester.

For the purposes of this study, the letter grades in both courses, CIS 2000 and BUAD 2120, were converted to ratio values as follows: (1) Grade of $\mathrm{A}=4.00$; (2) Grade of $\mathrm{B}=3.00$; (3) Grade of $\mathrm{C}=2.00$; (4) Grade of $\mathrm{D}=1.00$; and (5) Grades of $\mathrm{F}$, I or $\mathrm{WN}=0.00$. An "I" grade is a mark of incompletion for the course and a grade of "WN" is a withdrawal notification grade. The alpha level was set at .05 á priori.

This study was conducted at a four-year public university in Louisiana. Exploration of data occurred using Pearson's product-moment correlation. 


\section{Issues in Information Systems}

Volume 22, Issue 2, pp. 83-95, 2021

\section{Results}

The accessible population consisted of the 795 students who enrolled in CIS 2000 beginning in the Fall 2016 semester thru the Summer 2019 semester. The sample obtained from this group included $\mathrm{n}=295$ students who had valid grades and scores on record for CIS 2000, MOS Excel, and BUAD 2120. Not all students enrolled in CIS 2000 at the beginning of the Fall 2016 semester later enrolled in BUAD 2120, which led to their exclusion from the study sample. The gap between accessible population and sample used in this study may be explained by the students who (1) withdrew from or failed CIS 2000 or BUAD 2120, (2) failed to earn the MOS Excel certification, (3) withdrew from the university and/or transferred to other institutions before taking BUAD 2120, (4) took CIS 2000 as an elective for a degree program that did not require students to take BUAD 2120, or (4) changed majors to degree programs that did not required them to take business statistics.

The first objective of this study was to determine if a significant relationship exists between the final grade in CIS 2000 and the score on the MOS Excel certification exam. A significant relationship was found between the final grade in CIS 2000 and the score on the MOS Excel, $r=0.408, p<.01$.

The second objective of this study was to determine if a significant relationship exists between the final grade in CIS 2000 and the final grade in BUAD 2120. A significant relationship was found between the final grade in CIS 2000 and the final grade in BUAD 2120, $r=0.239, p<.01$.

The third objective of this study was to determine if a significant relationship exists between the score on the MOS Excel certification exam and the final grade in BUAD 2120. A significant relationship was found between the score on the MOS Excel and the final grade in BUAD 2120, $r=0.127, p<.05$.

All correlational analyses are presented in Table 1.

Table 1: Results of Correlational Analyses

\begin{tabular}{|l|l|l|l|}
\hline$\underline{\text { Relationship }}$ & $\underline{N}$ & $\underline{R}$ & $\underline{P}$ \\
\hline CIS 2000 and MOS Excel & 295 & 0.408 & $<.01$ \\
\hline CIS 2000 and BUAD 2120 & 295 & 0.239 & $<.01$ \\
\hline MOS Excel and BUAD 2120 & 295 & 0.127 & $<.05$ \\
\hline
\end{tabular}

\section{Discussion}

The relationship between the students' final grade in CIS 2000 and the students' scores on the MOS Excel certification exam had the strongest correlation of any of the tested relationship and was significant at the .01 level. This strong relationship was logical as the focus of the CIS 2000 class is learning how to use Microsoft Excel and the final exam in the class is the MOS Excel certification exam.

The relationship between the students' final grades in CIS 2000 and the students' final grades in BUAD 2120 had the next strongest correlation that was also significant at the .01 level. While the relationship between the students' scores on the MOS Excel certification exam and the students' final grades in BUAD 2120 were significant at the .05 level, the strength of the correlation was weaker than the other two relationships. This weaker relationship as compared to the relationship between the final grades could be attributable to several items. 


\section{Issues in Information Systems}

Volume 22, Issue 2, pp. 83-95, 2021

The strength of the relationship between the final grades in the two classes may be attributable to general academic performance. Students can receive similar grades across numerous classes based on their academic abilities even if those classes have no connection to each other. Thus, the strength of the relationship may not really reflect the knowledge connections between the two students but more the relationships between students' academic abilities and grades among multiple courses.

Another possibility is related to the difference between the final grade in CIS 2000 and the MOS Excel certification score. The MOS Excel certification score is a measurement of a student's ability to complete certain tasks and projects in Excel in a given timeframe. The final grade in CIS 2000 consists of the grade on the MOS Excel certification exam as well as other homework assignments given in the class. While not common, a student can perform well on the MOS Excel certification exam without having done well on, or even completing, the homework in the class. Likewise, a student may do well on the homework, but perform poorly on the certification exam. As seen in the first relationship, a strong correlation exists between the CIS 2000 final grade and the MOS Excel certification exam score, but it is not a perfect correlation.

Based on the results, the researchers can say the answer to each research question is a yes with a caveat that the prediction of success is not a perfect prediction. Having one score or one grade allows a researcher to predict with some success the related score or grade, but none of the relationships are so strongly correlated that a researcher could predict the results with a $100 \%$ accuracy.

\section{Limitations}

While the results of this study show significant correlation for each of the relationships, the study does have limitations. First, the researchers conducted this study at one four-year public university in Louisiana. This study population may not be applicable to other populations. The study also consisted of historical data from 2016 through 2019. During this time, various admissions and academic policies changed which could affect the results.

Likewise, the study shows correlation, not causation. Other factors could contribute to the correlations between each of these groups. Researchers have noted some of these concerns previously. Abou-Sayf and Miari (2007) caution researchers to be wary of attributing the correlation between student performance in a prerequisite course and the targeted course for two reasons. First, correlation may partially be explained by the phenomenon that good students perform well in all their courses, not only because they performed

well in the prerequisite or target course. Second, students who successfully complete the prerequisite course have already persisted through one semester of coursework and not dropped out and, typically, are better students than those who did not persist. As such, higher performance from the targeted course could potentially be due to the population of students having more academic experience. A sample of these occurrences can be found in a 2008 study by Sibulkin and Butler that initially confirmed that a population of students who had successfully completed algebra before enrolling in a statistics course resulted in a significantly higher average course grade than students enrolling in the statistics course without successfully passing algebra. However, when researchers controlled for other factors, including GPA, gender, and year in college, success in completing algebra no longer significantly predicted outcomes in the statistics course. Abou-Sayf (2008) also points out that results may also be affected at institutions that allow students with extraordinarily strong academic history to waive prerequisite course requirements, thereby resulting in lower student outcomes in the targeted course. 


\section{Issues in Information Systems}

Volume 22, Issue 2, pp. 83-95, 2021

\section{Implications for Research and Practice}

Based on the limitations, researchers could conduct more studies and attempt to control some of the external factors, such as incoming test scores, high school GPA, and college GPA. By controlling for these factors, as Sibulkin and Butler (2008) did, the researchers can more clearly determine whether correlation is causation in the tested relationships. This implication is supported by other researchers in the field.

Karakaya, Eryilmaz, and Ceyhan (2018) posit that more studies should investigate the relationships between student success in chained courses. Furthermore, Karakaya et al. (2018) recommend prerequisite chains be validated to justify how effective they are in producing the desired student outcomes. This validation process is expected to provide curriculum designers with information to determine whether current approaches remain relevant or have become obsolete. The research questions for the current study seeks the same answers posed by Karakaya et al. (2018), where the goal is to determine whether student success in a target course is correlated to success in the prerequisite course. Future research may consider analysis of the correlation between grades in the finite math course and BUAD 2120.

Researchers could also conduct studies in a different manner to ascertain more information about the effect of prerequisite courses on subsequent courses. According to McCoy \& Pierce (2004), the best way to test whether a prerequisite course is adding the desired value by promoting student success is to compare the rate of student success between students with and without prerequisites in the target course. While this method may be imperfect, meaningful comparisons can be made by looking at the grades and withdrawal rates of the students who took the prerequisite courses and those that did not. Prior research has shown that prescribing the order in which two courses are taken sometimes results in no difference between student outcomes, which disputes the need for mandating students to take one course as the prerequisite to the other or limiting classes to only discipline-specific students (Connors \& Ruth, 2012). Results from Bashford (2000) imply that passing a prerequisite class may not actually mean the student is appropriately prepared for subsequent coursework. Bashford (2000) specifically points out the debate surrounding when students pass with a "C" grade in collegiate-level classes or when students pass lower-level development classes as potentially problematic.

These research suggestions show multiple ways that prerequisite courses can be studied to determine their effect on the subsequent courses. The results have implications for practice. Based on the results of this study, the researchers will not suggest the removal of CIS 2000 as a prerequisite for BUAD 2120. The instructor of the course could allow a sample of students into the BUAD 2120 course to allow for a comparison of two groups - one with the prerequisite course and one that does not have the prerequisite course.

The researchers, and other faculty members in the School of Business, will also continue to review prerequisites to determine if they are roadblocks to student progression and success. While some of this analysis can be included in scholarly research, many of these decisions will be made at the operational level within the School of Business.

\section{Summary}

As two faculty members disagreed as to the importance of a prerequisite CIS 2000 (Spreadsheet Applications) class on the subsequent success of students in a BUAD 2120 (Basic Business Statistics) class, researchers at the institution undertook a correlational analysis. This analysis was to determine to what 


\section{Issues in Information Systems}

Volume 22, Issue 2, pp. 83-95, 2021

extent student success in a Basic Business Statistics course could be attributed to success in the prerequisite Spreadsheet Applications course and/or the associate MOS in Excel certification exam score.

Using data from 2016 through 2019, the researchers examined 295 students with valid grades and scores in CIS 2000, BUAD 2120, and on the MOS in Excel certification exam. The Pearson product-moment correlation analysis showed significant relationships between the CIS 2000 final grade and the MOS in Excel certification exam score (at the .01 level), between the CIS 2000 final grade and the BUAD 2120 final grade (at the .01 level), and between the MOS in Excel certification exam score and the BUAD 2120 final grade (at the .05 level).

As correlation is not the same as causation and other factors could affect the relationships measured in this study, further study is appropriate to determine the true extent of the effect of the knowledge gained in CIS 2000 on student's success in BUAD 2120. This additional study can also be applied to other prerequisite courses and their subsequent courses. On a practical level, CIS 2000 will remain as a prerequisite course to BUAD 2120 as the answer to the research question did not disprove that success in CIS 2000 affected success in BUAD 2120.

\section{References}

Abou-Sayf, F.K. (2008). Does the elimination of prerequisites affect enrollment and success? Community College Review, (36(1), 47-62. Retrieved from https://journals.sagepub.com/doi/pdf/10.1177/0091552108319539

Abou-Sayf, F., \& Miari, S. (2007). How to determine course prerequisites: An IR perspective on what to do and what not to do. IR Applications, 14, 1-7.

Anderson, D. R., Sweeney, D. J., Williams, T. A., Camm, J. D., \& Cochran, J. J. (2020). Modern business statistics with Microsoft Excel. Cengage Learning.

Armstrong, W. B. (1998). Mandatory Skill Level Prerequisites: How Are Student Outcomes Affected? A Student Equity Approach. Retrieved from https://files.eric.ed.gov/fulltext/ED440688.pdf

Baard, V., \& Watts, E. W. (2008). The value of prerequisites: A link between understanding and progression. Retrieved from

https://ro.uow.edu.au/cgi/viewcontent.cgi?article $=2185 \&$ context $=$ commpapers

Ball, C. (1992). Ladders and links: Prerequisites for the discussion of an international framework of qualifications. New Zealand Qualifications Authority, Wellington, New Zealand.

Bashford, J. (2000). How well do prerequisite courses prepare students for the next course in the sequence? Information capsule. Retrieved from https://files.eric.ed.gov/fulltext/ED448799.pdf

Becker, H. (2014). Admission criteria for schools of business: Common prerequisites and academic performance in upper-level business coursework. Retrieved from https://stars.library.ucf.edu/cgi/viewcontent.cgi?article=5630\&context=etd 


\section{Issues in Information Systems}

Volume 22, Issue 2, pp. 83-95, 2021

Chaamwe, N., \& Shumba, L. (2016). ICT integrated learning: using spreadsheets as tools for elearning, a case of statistics in microsoft excel. International Journal of Information and Education Technology, 6(6), 435-440.

Chickering, A. W., \& Kuh, G. D. (2005). Promoting student success: Creating conditions so every student can learn. Retrieved from https://scholarworks.iu.edu/dspace/bitstream/handle/2022/23541/Promoting\%20student $\% 20$ succe ss-

$\% 20$ Creating $\% 20$ conditions $\% 20$ so $\% 20$ every $\% 20$ student $\% 20$ can $\% 20$ learn.pdf? sequence $=1 \&$ isAl lowed $=\mathrm{y}$

Choudhury, A., Robinson, D., \& Radhakrishnan, R. (2007). Effect of prerequisite on introductory statistics performance. Journal of Economics and Economics Education Research, 8(3), 19-30. Retrieved from https://www.abacademies.org/articles/jeeervol8no32007.pdf\#page $=27$

Conners, S. E., \& Ruth, D. (2012). Factors Influencing Success in an Introductory Entrepreneurship Course. Journal of Entrepreneurship Education, 15, 63. Retrieved from https://www.researchgate.net/profile/Havard_Asvoll/publication/272744642_A case study Acti on based Entrepreneurship education how experience problems can be overcome and colla boration problems mitigated/links/57dbca4a08ae5292a37887b6.pdf\#page $=69$

Duke, A. E., \& Strawn, J. (2008). Overcoming Obstacles, Optimizing Opportunities: State Policies to Increase Postsecondary Attainment for Low-Skilled Adults. Jobs for the Future. Retrieved from https://files.eric.ed.gov/fulltext/ED500607.pdf

Duncan, D. (1990). Personal computing proficiency as a business school prerequisite. Journal of Computer Information Systems, 31(1), 13-17. Retrieved from https://www.tandfonline.com/doi/pdf/10.1080/08874417.1990.11647109

Falcon, L. (2015). Breaking down barriers: First-generation college students and college success. Innovation Showcase, 10(6). Retrieved from https://www.league.org/innovationshowcase/breaking-down-barriers-first-generation-college-students-and-college-success

Gainen, J. (1995). Barriers to success in quantitative gatekeeper courses. New directions for teaching and learning, 1995(61), 5-14. Retrieved from https://onlinelibrary.wiley.com/doi/abs/10.1002/tl.37219956104

Grace, J. T., \& D'aoust, R. (2006). Evidence-based program requirements: evaluation of statistics as a required course. Nursing education perspectives, 27(1), 28-33. Retrieved from https://journals.lww.com/neponline/Fulltext/2006/01000/Evidence_Based_Program_Requirement s_Evaluation_of.9.aspx

Gupta, S., Harris, D. E., Carrier, N. M., \& Caron, P. (2006). Predictors of student success in entry-level undergraduate mathematics courses. College Student Journal, 40(1), 97-109.

Retrieved from http://eds.a.ebscohost.com/eds/detail/detail?vid=0\&sid=1eb80baa-b361-4bd1ac31-

6c177cfc06ed\%40sessionmgr4008\&bdata=JnNpdGU9ZWRzLWxpdmUmc2NvcGU9c210ZQ\%3 $\mathrm{d} \% 3 \mathrm{~d} \# \mathrm{AN}=20522366 \& \mathrm{db}=\mathrm{a} 9 \mathrm{~h}$ 


\section{Issues in Information Systems}

Volume 22, Issue 2, pp. 83-95, 2021

Hanna, M. E., Perdue, G., \& Waller, E. R. (2015). Student success in an investments course and the appropriate prerequisite course. Journal of Economics and Economic Education Research, 16(2), 137. Retrieved from https://www.abacademies.org/articles/jeeervol16no2.pdf\#page=143

Hindi, N. M., Miller, D., \& Wenger, J. (2002). Computer literacy: Implications for teaching a college-level course. Journal of Information Systems Education, 13(2), 143. Retrieved from http://jise.org/Volume13/n2/JISEv13n2p143.pdf

Hudon, J. (2016, July 27) Prior knowledge as an Unexpected Obstacle to Learning Retrieved from https://www.facultyfocus.com/articles/course-design-ideas/prior-knowledge-unexpectedobstacle-learning/

Islam, F., Gygi, J., Gardner, N. D., \& Gooch, R. (2005). Relevance of prerequisites to business statistics: Some preliminary hypotheses and tests. Journal of College Teaching \& Learning (TLC), 2(7). Retrieved from https://www.clutejournals.com/index.php/TLC/article/download/1846/1825

Islam, F., Khan, S., Wilson, I., \& Gooch, R. (2008). The value of prerequisite courses for statistics. The Journal of Business Inquiry, 7(1), 61-67. Retrieved from http://journals.uvu.edu/index.php/jbi/article/download/166/140

Jacobs, A., Robinson, D. F., \& DePaolo, C. A. (2019). Using excel to make strategic managerial decisions. Journal of Information Systems Education, 27(2), 2.

Johnson, M., \& Kuennen, E. (2006). Basic math skills and performance in an introductory statistics course. Journal of Statistics Education, 14(2). Retrieved from https://www.tandfonline.com/doi/pdf/10.1080/10691898.2006.11910581

Karakaya, M., Eryilmaz, M., \& Ceyhan, U. (2018). Analyzing Students' Academic Success in Pre-requisite Course Chains: A Case Study in Turkey. The International journal of engineering education, 34(2), 364-370. Retrieved from

http://user.atilim.edu.tr/ murat.karakaya/publications/73\%20Analyzing\%20Students\%20Academ ic\%20Success.pdf

Kline, D., \& Strickland, T. (2004). Skill level assessment and multi-section standardization for an introductory microcomputer applications course. Issues in information systems, 2, 572-578.

Retrieved from https://pdfs.semanticscholar.org/a793/048d425e03e06b689fcb1981540e03a660b3.pdf

Kuh, G. D., Kinzie, J. L., Buckley, J. A., Bridges, B. K., \& Hayek, J. C. (2006). What matters to student success: A review of the literature (Vol. 8). Washington, DC: National Postsecondary Education Cooperative. Retrieved from https://nces.ed.gov/npec/pdf/Kuh_Team_Report.pdf

Lai, G., \& Williams, D. (2017). Exploring Undergraduate Business Students' Difficulties in Learning Statistics. In Society for Information Technology \& Teacher Education International Conference (pp. 1954-1959). Association for the Advancement of Computing in Education (AACE). Retrieved from https://www.learntechlib.org/p/177487/ 


\section{Issues in Information Systems}

Volume 22, Issue 2, pp. 83-95, 2021

McCoy, E. D., \& Pierce, S. K. (2004). The Function of Course Prerequisites in

Biology. American Institute of Biological Sciences. Retrieved from

https://files.eric.ed.gov/fulltext/ED501350.pdf

Palocsay, S. W., \& Stevens, S. P. (2008). A study of the effectiveness of web-based homework in teaching undergraduate business statistics. Decision Sciences Journal of Innovative

Education, 6(2), 213-232. Retrieved from

https://onlinelibrary.wiley.com/doi/pdf/10.1111/j.1540-4609.2008.00167.x

Pascarella, E.T., \& Terenzini, P.T. (2005). How college affects students. San Francisco, CA: Jossey-Bass.

Pharris, L., Tarver, M. B., \& Penrod, C. (2020). The GMetrix Exam: A Comparison of Predictors of Success for the Microsoft Office Specialist in Excel Certification Exam. Journal of Research in Business Information Systems, 27. Retrieved from http://www.abis-fbd.org/wpcontent/uploads/2020/03/JRBIS-2020.pdf\#page $=32$

Plutsky, S., \& Wilson, B. (2000). Study to validate prerequisites in business communication for student success. Journal of Education for Business, 76(1), 15-18. Retrieved from https://www.tandfonline.com/doi/pdf/10.1080/08832320009599044

Sargent, C. S. (2013). Find it, fix it, and thrive: The impact of insisting on proficiency in prerequisite knowledge in intermediate accounting. Issues in Accounting Education, 28(3), 581597.

Sibulkin, A. E., \& Butler, J. S. (2008). Should college algebra be a prerequisite for taking psychology statistics? Teaching of Psychology, 35(3), 214-217.

Sirias, D. (2002). Using graphic organizers to improve the teaching of business statistics. Journal of Education for Business, 78(1), 33-37. Retrieved from https://www.tandfonline.com/doi/pdf/10.1080/08832320209599695

Soria, K. M., \& Mumpower, L. (2012). Critical building blocks: Mandatory prerequisite registration systems and student success. NACADA Journal, 32(1), 30-42. Retrieved from https://www.nacadajournal.org/doi/pdf/10.12930/0271-9517-32.1.30

Sparkman, L., Maulding, W., \& Roberts, J. (2012). Non-cognitive predictors of student success in college. College Student Journal, 46(3), 642-652. Retrieved from https://www.ingentaconnect.com/contentone/prin/csj/2012/00000046/00000003/art00018?crawler $=$ true \&mimetype $=$ application/pdf

Spinelli, M. A. (2001). The use of technology in teaching business statistics. Journal of Education for Business, 77(1), 41-44. Retrieved from https://www.tandfonline.com/doi/pdf/10.1080/08832320109599669

Timmerman, K., Raymer, M., Gallgher, J., \& Doom, T. (2016, August). Educational methods for inverted-lecture computer science classrooms to overcome common barriers to stem student success. In 2016 Research on Equity and Sustained Participation in Engineering, Computing, and Technology (RESPECT) (pp. 1-4). IEEE. 


\section{Issues in Information Systems}

Volume 22, Issue 2, pp. 83-95, 2021

Wilkerson, J. M., Palmer, D. W., \& Meyer, J. C. (2019). Disintegrating Business Degree

Curricula by Skipping Prerequisite Courses. Journal for Excellence in Business \& Education, $6(1)$.

Yukselturk, E., \& Bulut, S. (2007). Predictors for student success in an online course. Journal of Educational Technology \& Society, 10(2), 71-83. Retrieved from http://citeseerx.ist.psu.edu/viewdoc/download?doi=10.1.1.119.7249\&rep=rep1\&type=pdf\#page= $\underline{76}$

Zanakis, S. H., \& Valenzi, E. R. (1997). Student anxiety and attitudes in business statistics. Journal of Education for Business, 73(1), 10-16. Retrieved from https://www.tandfonline.com/doi/pdf/10.1080/08832329709601608

Zhao, J. J., \& Alexander, M. W. (2002). Information technology skills recommended for business students by Fortune 500 executives. Delta Pi Epsilon Journal, 44(3), 175-89. Retrieved from https://www.learntechlib.org/p/95719/ 